Original Contribution

\title{
NATURE OF PHYSICIANS' MISTAKES AS A MODULE IN MEDICAL ETHICS TEACHING AT THE MEDICAL UNIVERSITY - PLOVDIV
}

\author{
M. Liotchkova1, V. Mihaylova ${ }^{1,2}$, I. Bivolarski ${ }^{3}$ \\ ${ }^{1}$ Department of Health Care Management, Faculty of Public Health, Medical University-Plovdiv, \\ Bulgaria \\ ${ }^{2}$ Department of Preventive Medicine, Faculty of Public Health, Medical University-Sofia, Bulgaria \\ ${ }^{3}$ Department of General and Clinical Pathology, Medicine Faculty, Medical University-Plovdiv \\ Bulgaria
}

\begin{abstract}
Purpose: Taking into consideration the crucial importance of patients' health insurance as a public priority and an indicator for the quality of health care provided, we set ourselves the objective to bring additional light on the bioethical and deontological aspects of the issue known as 'medical errors' and their classification adapted to the methods of teaching bioethics and the Medical University of Plovdiv.

Methods: Our methods are based on available literature and on expert consultations and assessment by leading legal experts in the field that is discussed.

Results: The module related to the interconnection between law and medical ethics occupies a special place within the subject with a total of 30 teaching hours including lectures, seminars, clinical cases and testsolution. This module includes $1 / 3$ theoretical discussions with medical and law content and 2/3 practicalsituational and casuistic approach. Their role is interpreted from the point of view of the conceptual (linear and delimitative) model in ethics and law. Accent is put on legal and deontological aspects of the nature of medical errors taking into account the guilty or not guilty act or inaction that have led to it.

Conclusion: The students have got awareness that Law and Medical Ethics are disciplines with frequent areas of overlap, yet each discipline has unique parameters and a distinct focus.
\end{abstract}

Key words: Bioethics training, students, ethics and law, medical error, case

\section{INTRODUCTION}

Health systems and health policies within the EU become more and more complex and interconnected. This tendency raises multiple health- and political issues related both to the problem of healthcare and to the prevention of medical errors in particular. The Eurobarometer survey carried out by the Directorate General of Health and Consumer Protection in the 28 Member States of the EU, as well as in associated countries and candidate countries in 2005 was an important step towards procurement of safe medical service (1).

According to WHO patients' security appears to be the primary public priority. In a number of countries medical errors are an indicator of the quality of the provided healthcare; they

*Correspondence to: Vanina Mihaylova,
Department of Preventive Medicine, Faculty of
Public Health, Medical University-Sofia;
Department of Health Care Management, Faculty
of Public Health, Medical University-Plovdiv, blvd.
"V.Aprilov"15a, GSM: +359887609898,e-mail:
vanina_delfi@abv.bg

Trakia Journal of Sciences, Vol. 13, № 4, 2015 also indicate the probability risk in terms of patient's security (2-4). Within this meaning medical audit is pointed out as a risk management tool aiming at their prevention (58).

Research in this field shows that a considerable part of the cases of patients who have become victims of medical errors could have been avoided in due course. The economic aspects of medical errors are analyzed by leading authors in this field (9-11), and in Bulgaria by Stoyanova, R., R. Raycheva., R. Dimova (2012) (12).

At this stage the scientific terminology in this specific area of medical law, particularly of medical errors, is still open-ended. A fundamental design in this direction is made by M. Lyochkova (1999) (13).

The main goal of the present work is to bring additional clarity and develop the bioethical and deontological aspects of the problem of medical errors and most specifically of their classification, adapted to the method of 
training process. The student have got awareness, that law and medical ethics are disciplines with frequent areas of overlap, yet each discipline has unique parameters and a distinct focus. To better understand the relationship between law and medical ethics, these materials will briefly review: Definitions - Sources of Authority; Conceptual Models; Roles of Medical Ethics and the Law. In the course of practicing medicine, a range of issues may arise require consultation from either a lawyer, a risk manager, or an ethicist. The role
LIOTCHKOVA M., et al. of lawyers and risk managers are closely linked in many health care institutions. There are, however, important distinctions between law itself and risk management. When legal and risk management issues arise in the delivery of health care, there may be ethical issues, too (14).

A way to consider the relationship among the three disciplines is through illustration them in conceptual models (Figure 1).

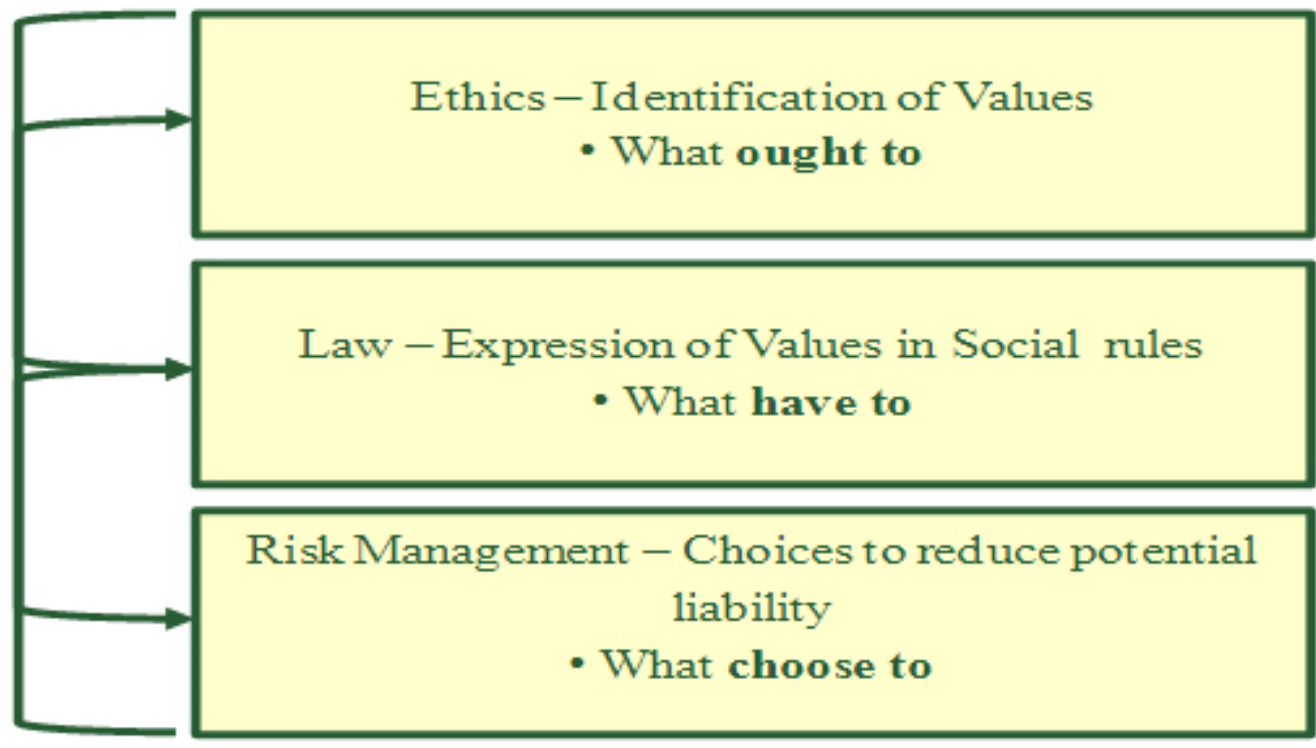

Figure 1. Modification of conceptual model of law and ethics - Linear-Distinctions (13)

Within their distinctive roles, the disciplines of law and medical ethics nevertheless significantly overlap (Figure 2).

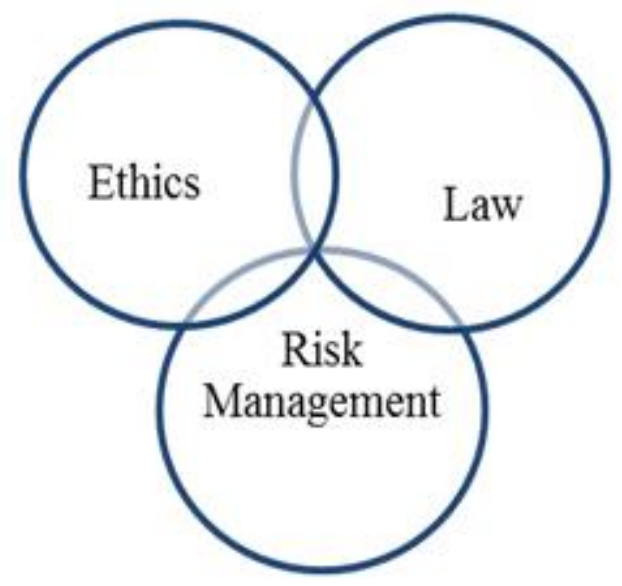

Figure 2. Conceptual Model - Interconnectedness https://depts.washington.edu/bioethx/topics/law.html

Nature. In our everyday conversations we are accustomed to saying and hearing that an unfavorable outcome of the treatment resulted from a "doctor's error" or an "error of the doctor". This expression is often used in medical science and practice, as well as in forensic medicine. It is inaccurate from the legal standpoint. This notion includes, on the one hand, the voluntary misunderstandings of the doctor upon fulfilling his or her professional duties, owing to the imperfections of modern medical science and the testing methods, as well as to the specifics of the human organism and the influence of various 
subjective conditions. On the other hand, doctors' error is also the issue when the unfavorable outcome is due to insufficient knowledge or to negligent, careless or presumptuous execution of duties. Therefore, "doctors' error" is understood as either a culpable and innocent action or omission.

The death or damage to the patient's health occurred cannot always be ascribed as a fault of the doctor. Such an unhappy outcome may be due to the individual specifics of the organism, which sometimes remain unknown to the doctor (for example, in cases of narcosis, vaccination, etc.). The technique of a certain medical treatment or the type and dosage of the medicinal product may be in total conformity with the requirements of science and nevertheless an unfavorable outcome may result caused by the individual unpredictable characteristics of the organism treated. Sometimes such an outcome may be due to an accident - unfavorable or unforeseen turn of events.

Specification of the causes of negative results concerning the patient's health has a significant, sometimes forensic importance. The concept of iatrogeny (coming from the Greek words "iatros" - healing person and "genia" - bring about, lead to), which was introduced in ancient Greece, is of similar but not equivalent significance. Iatrogeny constitutes a process expressed in deterioration of the condition of the patient (including a lethal outcome), caused by a medical person; this also includes medical manipulations performed by a nurse or obstetrician (for example, giving a shot of an oleos solution of an antibiotic venously, which leads to pulmonary fat embolism). Iatrogeny also includes the negative psychological impacts of unthoughtful statements by personnel, most often in the confined environment of the hospital. The influence of the implication of something said by an authoritative nurse is so important for the patient that during the 1990s a special term was introduced in for it nocebo. The nocebo effect is the opposite of the placebo effect and is manifested in the absence of effect of a given medication if a doctor has expressed loudly an opinion in doubt of its positive impact.

In view of the structure of the material taught we have included the following topical units.

\section{TYPES OF ERRORS}

1. The errors due to objective reasons are the following:

- Errors, due to the imperfection of medical science. Medicine is not an all- conquering science because of the extreme complexity of the human organism and its physiology. That is why such errors are admitted by experience doctors as well. On the other hand, the imperfection of medicine is due partly to the constant changes of disorders. Quite often the morbidity causes rapidly become resistant to new methods or medicinal products, which are especially manifested upon the introduction of antibiotics, thus making treatment difficult. A fact that should also be noted is that a change in the typical progress of diseases with the manifestation of new symptoms and a morphological finding can also occur under the influence of the therapy performed. The condition is called pathomorphosis.

- Doctors' errors may also be due to other objective causes, for example lack of time or conditions for work. Very often the cases are such that it is necessary that the doctors undertake action immediately without having the time to examine the ill person in detail and specify the diagnosis. This is especially relevant in surgery. It is even possible that intervention becomes necessary outside the clinical setting. The absence of the relevant medical and technical equipment may lead to an unfavorable outcome. These errors could not be ascribed as a fault to the doctor either.

\section{Errors due to subjective reasons}

Doctors' errors are discussed in cases of completely subjective causes as well, for example:

- insufficient knowledge;

- negligent fulfillment of obligations; provided.

- failure to use the medical equipment Such errors of subjective nature are legally qualified as „negligence”, „inadvertency”, „conceit” or even „intention”. The error is material, when it is a thought not corresponding to reality. The logical error in its turn is a violation of formal logic. It is a misrepresentation of the relation between separate thoughts. An error of any nature whatsoever could lead to incautious action or omission, which in its turn could cause quite unfavorable consequences in therapy resulting in seeking responsibility from the doctor because such an error is ascribed as a fault to him or her.

II. DOCTORS' ERRORS BY STAGES OF THE MEDICAL-DIAGNOSTIC PROCESS 1. The diagnosis - a first stage in the doctor's medical activity

It is a brief doctor's conclusion concerning the type of the basic disorder, the background and accompanying disorders, their complications, 
LIOTCHKOVA M., et al.

stages and dynamic of development, the stage of its development and the patient's condition. The correct construction and arrangement of the diagnoses requires observance of the WHO recommendations included in the latest, $\mathrm{X}$-th revision of the International Classification of Diseases.

Among subjective errors the most numerous ones consist of errors due to insufficient preparation and experience of the doctor. The medics acquire certain knowledge in the process of university studies of medicine with which such medics can start their practice as physicians in general medicine. After that, however, it is necessary for the medic to acquire and accumulate experience. The young doctor is to master medical technique and practical habits. But this takes time. If the doctor still remains at his or her previous level after the lapse of a certain period of time sufficient for acquiring these habits and experience, this then constitutes guilty inaction, which leads to liability of the doctor in the cases when damage is caused. It is possible to ascribe as a fault to the doctor both the untimely completion of medical experience and knowledge, and the premature exercising of interventions requiring such experience and knowledge. For example, in case the beginner surgeon or the neurosurgery specialist performs a trepanation of the skull, which ends lethally, the actions of the neurosurgeon may be accepted as accidents while the actions of the beginner physician - as conceit.

Insufficient experience in recognizing the symptoms of individual diseases or the nature or manner of their development and so on is the reason for wrong determination of the diagnosis. The doctor can easily avoid such a mistake by consulting with specialists or by referring the patient to a specialist. Failure to comply with that leads to liability.

Another reason of subjective nature often leading to wrong determination of the diagnosis is the non-performance of obligations on behalf of the doctor. Thus, the tests inadequately undertaken constitute negligence. It is possible that a test of the same type is not carried out repeatedly and the doctor satisfies himself with a single testing instead (for example just one radiogram while it is necessary to capture the organ from several different angles). A diagnosis not determined or delayed also constitutes nonperformance of obligations. It is not correct to determine a diagnosis over the telephone, even after collecting detailed data of the antecedent history, the examination and condition of the patient. Determining a diagnosis in this manner constitutes direct negligence. It constitutes gross negligence to exchange testing samples and test results. Except by the personnel of the medical establishment, this can also be performed willfully by patients with the purpose of concealing facts having forensic importance. That is why in the cases when a given material has been brought in for testing personally by a patient or his/her relatives, this fact should explicitly be recorded in the medical documentation.

Not utilizing the prescribed devices or apparatuses (thermometer, stethoscope, blood pressure monitor, etc.) or the inability to use more complex medical equipment also constitutes culpable action or omission.

A doctor maintaining a wrong diagnosis he or she has initially assumed but being later on refuted by newly recognized or newly manifested symptoms of the disease, acts incautiously.

It is not negligence, however, to act according to one or another scientific theory/school of thought upon determining the diagnosis, provided both are officially maintained at the time of the disease. In such cases the doctor is entitled to a choice.

It is not possible to consider it doctor's negligence when a diagnosis has been incorrectly determined as a result of material omissions made - deliberately or negligently on behalf of the patient upon providing data for the antecedent history. In all cases, whenever the doctor causes damage due to lack of knowledge or incautiousness upon determining the diagnosis then such doctor bears criminal and civil liability.

\section{The therapy - a second stage of the doctor's activity}

After specifying the diagnosis the doctor proceeds to the treatment. The treatment (therapy) is that part of the doctor's activity whose subject is the application of methods established by medical science for curing diseases and reducing their unfavourable consequences in case healing is impossible.

The subjective reasons, which may cause errors in therapy, can as well be the factors specified herein above:

Whenever the physician in general medicine or specialist starts servicing the patient, which he or she cannot perform with the knowledge and experience available or which he or she can perform but not adequately enough, then such doctor thus violates his or her professional 
duties. Consultation can be sought in case the doctor does not know how to help his patient or in case the patient doubts the doctor's knowledge.

Undertaking therapy in one or another manner prescribed by medical science does not constitute an error. In this case the doctor is entitled to make a choice if he or she has taken into account the individual characteristics of the patient. Thus it is not negligence to undertake even dangerous methods of treatment (for example radiation with isotopes) if the patient's condition so requires and there is no other opportunity.

Another cause of subjective nature, which can lead to unfavourable results, is the nonperformance of activities prescribed by medical science although they are known to the doctor.

Inaction often leads to dangerous results just like incorrect action. For example, it is inadmissible that a person who has received arm injury in non-hygienic environment, not to receive anti-tetanus immunization. It is incorrect not to perform control examinations and tests during the treatment (for example $\mathrm{X}$ ray examinations and radiograms, blood, urine analysis, etc.), through which it is possible to easily and indisputably ascertain the progress of the disease.

The doctor is obliged to give the patient accurate instructions in relation to the method of taking and the quantity of medications,
LIOTCHKOVA M., et al. especially when medications containing toxic substances are concerned. It is an important obligation of the doctor to explain whether the medication is for external or for internal treatment and how it is to be taken. Failure to provide such instructions is also negligence.

The absence of sufficient experience in carrying out various medical manipulations is also a doctor's error and can lead to serious damages and liability (for example puncture of the colon in rectoscopy, or of the urinary bladder in cystoscopy or of the palate by a drill).

On the contrary - a technically perfect performance of a manipulation can also lead to grave iatrogeny if it is not consistent with the characteristics of the disease, which is the cause for said intervention. A specific example is the biopsy of nevus suspicious of malignization. The correct surgical conduct, which is lifesaving, is full excision - in width and in depth. In this case the rule to be observed is that the diagnostic manipulation /taking of material for testing/ should at the same time be curative /complete excision of the tumour process/. If the material has been taken by means of incision biopsy /partial cutting/ and the morphological finding is a melanoma, it is almost certain that the surgical manipulation has speeded up the process of metastasis formation and has contributed to the unfavourable outcome of the disease (Scheme 1).

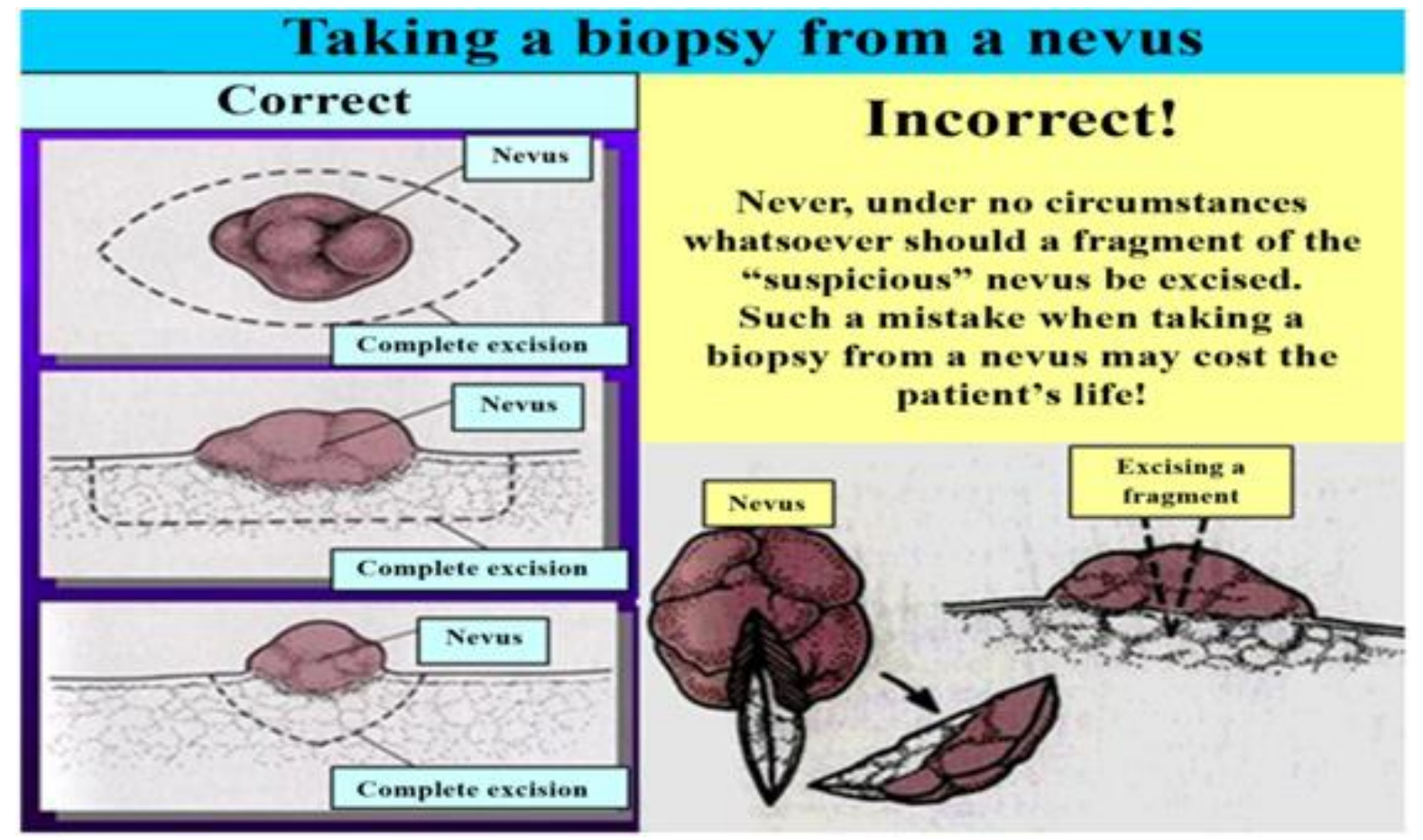

Scheme 1. Taking a biopsy from a nevus

Trakia Journal of Sciences, Vol. 13, № 4, 2015 
It is not admissible, for example, to conduct treatment or surgery in case the ambient environment of the patient does not have the relevant temperature (for example temperature in the operating room of $14-15^{\circ} \mathrm{C}$ ). Whenever certain treatment methods require that the doctor should have an assistant, it is not admissible that the doctor should act alone under normal conditions. It is gross negligence to prescribe medicinal products in dosages exceeding the admissible ones. Overdosing can be absolute - when it is inadmissible in relation to any person whatsoever, or relative when it is inadmissible in relation to a specific person. Carcinogenic (cancerogenic) substances cannot be prescribed as medications. One medication cannot be prescribed instead of another either (for example, medications causing tachycardia instead of medications retarding the cardiac rhythm), i.e. a clinical pharmacist should be associated within the structure. Recipes and written prescriptions must be carefully and legibly written and must contain all necessary elements. Failure to abide by these rules also constitutes negligence.

The theoretical material set forth is supported by illustration with cases from forensic medical practice from which the following medical cases are quoted herein:

\section{Cases:}

- A woman in labour died at the Obstetrics and Gynecology Ward of the Multi-profile Hospital of Active Treatment after caesarian operation and followed hysterectomy due to an abundant hemorrhage. During her pregnancy the woman was referred to different consultants due to unclear complaints but in the reporting document from Prenatal Consultations entitled ", Record of the pregnant woman and woman in labour", with which the woman was admitted for giving birth those consultations were not recorded by the GP (General Practitioner). It is not known whether examinations of the cardiovascular and respiratory system were performed (in relation to these systems "no specific abnormalities", "no changes" have been recorded); during the autopsy cystic lungs and cardiac muscle dystrophy were found. The history of birth giving is written with unclear corrections and rough strikethroughs. There are strikethroughs of the diagnosis; there is a correction of times, dates, etc. In addition to that, it has been recorded in one place that the woman in labour had two children, while in another place it is written the she had three children.
LIOTCHKOVA M., et al.

Almost always (as evidenced by the case quoted above) errors are intertwined with documentary violations.

- A patient diagnosed with "hemoptoe" (according to the pathoanatomist it was most probably due to corroded or torn vessel of the lung 20 years after an operation from echinococci?!) was refused admission to hospital several times. He was given some shots but it is not known what and by which doctors. Upon the manifestation of unconvincing psychic symptomatic he was admitted to a Psychiatric Hospital, in where he was put in a "straightjacket" and was treated for schizophrenia, after which the patient died. During the investigation no data was discovered for a crime although certain omissions in terms of the ,timely hospitalization in a psychiatric hospital in the event of an acute hemorrhage in the lung " were pointed out.

\section{Question: What kind of medical/doctor's error was admitted in the cases described?}

1.Subjective - impossibility to work with medical equipment

2.Objective - absence of a suitable location and conditions for work

3.Subjective - negligence

4.Accident

5.Subjective - intent

- In a maternity hospital after a caesarian operation $630 \mathrm{~cm}$ of incompatible blood type was prescribed and infused twice to the birth giving mother - due to a technical error of the laboratory assistant upon determining the blood type. The operating surgeon definitely refused to perform the necessary tests and control with the argumentation that he "could not perform the laboratory assistant's work".

\section{Comment}

In the cases the opinion of the forensic expertise is firm - the actions of the attending physician and respectively of the operating surgeon, of the medical nurse, laboratory assistant and specializing intern are in a causation relation with the result occurred death. There is an independent joint contribution to the criminal result by several persons, as each one of them is liable according to the degree of his/her joint contribution and according to a specific fault. In most of the proceedings reviewed the direct testing for compatibility between the recipient's blood and the donor's blood have not been performed in a manner prescribed in the Instruction and the biological testing for 
tolerance to the donor's blood has not been performed either.

This leads us to the assumption that even in successfully performed blood infusions these tests are not regularly performed and the results of the tests are recorded in the Application - Sample 4 not after turning the infusions on but formally after the transfusion. It is obvious that sometimes the expertise, and respectively the court advocate in relation to the existence of an alternative probability that death could have occurred without the incriminated act of the medical official against whom the investigation is conducted. We believe such an opinion is not always objective.

Studying omissions and errors in keeping medical documentation from the organizational aspect reveals the basic preconditions and tendencies in them and at the same time to a certain extent is a good base for the implementation of automated systems for health care management.

\section{CONCLUSION}

Errors are inevitable in the practice of medicine. The module entitled „Ethical and Legal Dimensions of Medical Errors" within the training in Bioethics has been introduced at the Medical University - Plovdiv, Department of Social Medicine and the specialty of Health Care Management (currently within the Faculty of Public Health) since the middle 1990s. It serves an acknowledgment of specific duties and responsibilities toward the individuals and society. The students become the awareness, that mistakes undermine patients trust in physicians and the medical system. The material taught is accepted by students with great interest; it provokes ardent discussions and leaves a durable trace in the professional realization of the graduating medics and future health care system professionals.

\section{REFERENCES}

1. Patient Safety - Making it Happen! Luxembourg, 5 April 2005 Luxembourg Declaration on Patient Safety, European Commission DG Health and Consumer Protection.
LIOTCHKOVA M., et al.

2. Kohn, L.T., Corrigan J.M., Donaldon M.S., eds. To err is human: Building a safer health system, Washington,(DC): National Academy Press, 1999.

3. Chenot, T.M. Patient safety and the ambulatory care setting. Northeast Florida Medicine, 58,3:23-6, 2007.

4. Ollenschlager, G. Medizinische Risiken, Fehler und Patienten - sicherheit. Schweizerische Arztezeitung/Bulletin des medecins suisses / Bollettino dei medici svizzeri, 82:№26, 2001.

5. Aspden, P., Wolcott J.A., Bootman J.L. Preventing medication errors. Washington (DC): National Academy Press, 2007.

6. Petrova, Zl. The medical audit as a medical risk management instrument. Scripta Scientifi ca Medica 43:211-15, 2011 (In Bulgarian).

7. Shopov, D., Torniova, B., Raykova, E. Psychological climate in hospitals as a factor in improving the quality of medical care. General Medicine, 11(1):30-34, 2009.

8. Leape, L.L. Preventing medical injury, QRB quality. Review Bulletin, 19(5):144149, 1993.

9. Shreve, J., Van Den Bos J., Gray T. The economic measurement of medical errors, society of actuaries.,2010; http://www.soa.org/fi les/pdf/researcheconmeasurement.

10. Mello, M.M., Studdert, D.M., Thomas E.J., Yoon, C.S.,Brennan, T.A. Who pays for medical errors? An analysis of adverse event costs, the medical liability system, and incentives for patient safety improvement. Journal of Empirical Legal Studies,4:8358602007.

11.Thomas, E.J., Studdert, D.M., Newhouse, J.P., et al. Costs of Medical Injuries in Utah and Colorado. Inquiry, 36(3):255-64,1999.

12.Stoyanova, R., Raycheva, R., Dimova, R. Economic Aspects of medical errors. Folia Medica, 54(1): 58-64, 2012.

13.Liochkova, M., Hristozova, E., Lesinska, M., et al. Medical ethics. Plovdiv, HMI (In Bulgarian), pp 153-154, 1999.

14.Brock, L., Mastroianni, A.Clinical Ethics and Law. University of Washington School of Law, 2013.

https://depts.washington.edu/bioethx/topics/ law.html. 